\title{
DEBATES CONTEMPORÂNEOS SOBRE AUTONOMIA PRIVADA DECISÓRIA: TRANSGÊNEROS, IDENTIDADE GENÉTICA E EUTANÁSIA
}

\author{
Riva Sobrado de Freitas* \\ Danielle Jacon Ayres Pinto*
}

RESUMO: Nesse artigo dirigimos nossos estudos para os movimentos sociais que emergiram na última década do século XX. Para esses movimentos, a luta por redistribuição de riquezas travada isoladamente não bastava, porque não contemplava a necessidade do reconhecimento da diversidade de cada segmento social em busca de sua emancipação. Como uma das formas de superação desses impasses, enfocamos em nosso trabalho, a necessidade da reconfiguração do Direito ao próprio Corpo, redesenhando seu conteúdo sob a ótica da Autonomia Privada Decisória. O artigo trabalha também com a possibilidade dessa reconfiguração tornar-se um valor político nacional capaz de aumentar a influência do Brasil regionalmente.

Palavras-Chave: Direitos Fundamentais, Autonomia Privada Decisória, Direito ao Próprio Corpo, Privacidade Decisória, Influência Regional, América do Sul.

\section{CONTEMPORARY DEBATES ON DECISION-MAKING AUTONOMY: TRANSGENERY, GENETIC IDENTITY AND EUTHANASIA}

\begin{abstract}
ABSTRAT: In this article we direct our studies to the social movements that emerged in the last decade of the twentieth century. For these movements, the fight for the redistribution of wealth alone was not enough, because it did not contemplate the need to recognize the diversity of each social segment in search of its emancipation. As one of the ways to overcome these impasses, we focus on our work, the need to reconfigure the Right to the Body itself, redesigning its content from the standpoint of Private Decisive Autonomy. The article also works with the possibility of this reconfiguration becoming a national political value capable of increasing the influence of Brazil regionally.
\end{abstract}

Keywords: Fundamental Rights, Private Decision-making Autonomy, Right to Own Body, Decisional Privacy, Regional Influence, South America.

\footnotetext{
* Coordenadora e Docente do Programa de Pós-Graduação em Direitos Fundamentais da UNOESC/SC. Professora de Direitos Humanos da Universidade Estadual Paulista “Júlio de Mesquista Filho” UNESP/Franca (aposentada). Membro do Grupo de Pesquisa Observatório do Estado da UFSC. Contato: rivafreit@gmail.com

* Professora Adjunta do curso de Relações Internacionais da Universidade Federal de Santa Catarina/UFSC. Coordenadora do Grupo de Pesquisa Observatório do Estado da UFSC. Contato: djap2222@yahoo.com
} 


\section{INTRODUÇÃO}

O presente trabalho busca identificar alguns desafios presentes nas lutas por emancipação social que tiveram a sua origem a partir da última década do século XX, época também conhecida como pós-socialista, período de grande proliferação de lutas sociais que pleiteavam a satisfação e a superação de outros tipos de demandas e injustiças, para além da redistribuição de riquezas, que até então constituíam o cerne das reivindicações trabalhistas nos conflitos capital/trabalho.

Para esses movimentos, a questão central era o reconhecimento e o respeito pela diversidade de cada segmento social. Os novos atores sociais e os novos grupos de libertação pleiteavam a construção de uma sociedade pluralista e entendiam que essas distorções não seriam corrigidas apenas por meio de uma justiça redistributiva, divergindo dessa forma, das lutas sociais tradicionalmente travadas no século vinte pelos sindicalistas.

Entretanto, em que pese a proliferação das lutas emancipatórias pelo reconhecimento terem alcançado grande visibilidade a partir da década de noventa do século passado, o que se observa é que esses movimentos também dirigiram suas demandas ao Estado Social de BemEstar, assim como os movimentos operários do século XX, e também confiaram em seus mecanismos de intervenção e regulação para a promoção do reconhecimento que pretendiam.

Ocorre, entretanto que o fenômeno da globalização na economia e a internacionalização do capital já tinham promovido uma profunda erosão na estrutura do Estado Social de BemEstar e seus mecanismos de intervenção e de regulação já estavam bem menos operantes. Pleitear a emancipação social e o reconhecimento através da regulação se tornava cada vez mais inviável.

Observou-se a partir de então, o aprofundamento das reivindicações em prol do reconhecimento e o abandono, de forma progressiva, das lutas por redistribuição de riquezas. Esse fato, em que pese haver contribuído para o aprofundamento de algumas lutas sociais (gênero, por exemplo), promoveu a atomização e a segregação entre os movimentos, de maneira geral. Esses passaram muitas vezes a competir entre si, o que dificultou a articulação de um projeto comum de lutas por emancipação social.

O separatismo e a segregação entre os movimentos sociais contribuiu de forma significativa para a inoperância e para o esvaziamento das propostas de transformação social, o que acabou por acirrar a intolerância, recrudescer o machismo, o autoritarismo e a discriminação sexual, promovendo um grande retrocesso. 
Uma vez identificados os desafios, aos movimentos sociais contemporâneos por libertação, o problema que se coloca é saber como superá-los. Sem abandonarmos absolutamente as propostas de luta baseadas na solidariedade entre os movimentos, e no combate concomitante ao colonialismo e ao patriarcado, capazes de gerar respectivamente o racismo e a discriminação sexual, entendemos que talvez a grande inovação, no que toca à possibilidade de superação desses impasses e complementação dessas lutas, passa sobretudo pela construção da identidade pessoal de cada indivíduo.

Nesse sentido, a reconfiguração da Autonomia Privada, nos moldes de uma privacidade decisória, ou seja: uma Autonomia Privada Decisória, poderia propor avanços significativos no empoderamento do próprio corpo, no direito de decidir sobre a sua orientação sexual, sobre questões de gênero, etc, sem intervenções do Estado ou da própria comunidade.

Nosso trabalho vai centrar-se no desenvolvimento das bases teóricas relativas à construção de uma Autonomia Privada Decisória, e na verificação de sua real contribuição para os movimentos sociais contemporâneos que postulam o direito ao próprio corpo, dentro de uma perspectiva da privacidade decisória.

Dessa forma, nosso primeiro tópico será destinado a identificar alguns impasses importantes colocados hodiernamente aos movimentos sociais pela libertação e pelo reconhecimento, trabalhando logo a seguir as bases teóricas para a construção da Autonomia Privada Decisória, fundamentada na privacidade decisória, para posteriormente verificar a sua real contribuição para o entendimento e superação dos impasses às lutas que postulam questões de gênero, identidade sexual, identidade genética, direito ao próprio corpo, transexualidade, direito a morrer com dignidade, etc.

Para tanto nossa pesquisa teórica procurou pautar-se em pesquisa bibliográfica, consubstanciada na leitura de diversas obras, utilizando-se do método dedutivo.

Informamos outrossim que as ideias desenvolvidas nesse trabalho foram objeto de aulas ministradas pela autora em Roma - Itália, junto à ADAPT, em curso realizado em Janeiro de 2017.

\section{A REDEFINIÇÃO DO DIREITO A AUTONOMIA PRIVADA E SUA REPERCUSSÃO NA CONSTRUÇÃO DA IDENTIDADE PESSOAL}


A Liberdade, uma das primeiras aspirações da modernidade significou desde então um espaço sem ingerências de terceiros de forma a garantir a qualquer indivíduo a possibilidade de sua autodeterminação sem submissão à outrem. Caracterizou-se portanto, desde o século XVIII, em uma esfera, garantida pelo ordenamento jurídico, dentro da qual o indivíduo poderia efetuar as suas escolhas , em oposição aos interesses do Estado, e da comunidade, onde não estaria obrigado nem proibido por qualquer determinação legal.

Entretanto é importante salientar que a Liberdade para os gregos era formulada de maneira distinta. Consistia somente na prerrogativa conferida aos cidadãos de participar das decisões políticas e nisso diferenciava-se substancialmente do liberalismo moderno (COULANGES, 1971). A realização da Liberdade, para os antigos, portanto, centrava-se unicamente na primazia da participação política, sem quaisquer restrições previamente estabelecidas. Assim, o cidadão, poderia propor qualquer alteração legislativa, tomar qualquer decisão política, sem qualquer temor de que ela fosse considerada ilegal.

De outra parte, e nisso também constituía a Liberdade, o cidadão na antiguidade, apenas haveria de se submeter às leis que ajudara a elaborar, participando da sua construção através do procedimento estabelecido pela Democracia Direta (HABERMAS,2003).

A Liberdade para os antigos consistia portanto no exercício coletivo e direto de diferentes parcelas da soberania popular. Dessa forma, poderia deliberar em praça pública, votar as leis sem nenhuma vedação prévia, etc., entretanto deveria haver submissão plena à autoridade dessa decisão, e como não era possível nenhuma restrição à atividade legislativa, qualquer tema poderia ser objeto de intervenção dessa natureza, inclusive ações privadas de modo geral, tais como: opção religiosa, relações domésticas, etc. As leis poderiam regular inclusive os costumes. Como observa Benjamin Constant, o indivíduo exerceria plenamente a sua soberania popular nas questões públicas, entretanto seria absolutamente submisso, como um escravo, nas questões de ordem privada (CONSTANT, 1819).

Entretanto, no século XVIII, com o advento da Modernidade e a construção dos pactos constitucionais, os direitos individuais, tais como: o direito de escolher o trabalho, de expressar suas opiniões, de efetuar a opção religiosa, passaram a ser configurados como liberdades individuais, ou seja: um espaço para a autodeterminação pessoal, oponível contra possíveis intervenções, especialmente aquelas provenientes do Estado, significando dessa maneira, esferas de Autonomia Privada capazes de constituir verdadeiros escudos de proteção às atividades deliberativas estatais, inclusive as legislativas. O temor à “tirania da maioria” passou a ser real, a partir de então. Assim , com Modernidade, e a construção do Estado Liberal 


\section{DEBATES CONTEMPORÂNEOS SOBRE AUTONOMIA PRIVADA DECISÓRIA: TRANSGÊNEROS, IDENTIDADE GENÉTICA E EUTANÁSIA}

Constitucional, não foram mais aceitas as instituições que pudessem restringir liberdades individuais. (CONSTANT, 1819).

Dessa maneira, a Liberdade na Modernidade deve ser compreendida como a Liberdade negativa, ou seja, uma esfera de Autonomia Privada, onde a intervenção do Estado ou da comunidade deve ser negada. Ela se estabelece definitivamente no direito privado através do ideário liberal a partir do século XVIII (MEIRELES, 2009), como um valor essencial à condição humana, mas perdura até os dias atuais como um direito humano fundamental à dignidade pessoal de cada indivíduo.

Consoante o que foi exposto seria possível constatar uma contraposição entre soberania política, relativa ao exercício da atividade legislativa e Autonomia Privada, enquanto uma restrição, um escudo oponível à atividade estatal de legislar? A esse respeito Habermas observa que não existe uma tensão entre ambas, mas apenas uma relação de complementaridade, na medida em que a Autonomia Privada confere legitimidade à Autonomia Pública e dessa forma, a legitimação do Poder do Estado se assenta na Autonomia Privada dos cidadãos (HABERMAS, 2003).

Ainda nesse sentido, Stuart Mill, evidenciando uma preocupação em relação às decisões tirânicas da maioria, defende a proteção da diversidade entre os membros da sociedade. Para o autor, a única justificativa pela qual a sociedade (ou a humanidade) poderia individual ou coletivamente interferir na liberdade de decisão de seus membros seria em situações onde essa intervenção tivesse por escopo a prevenção de danos à própria sociedade. Para Mill, a única parcela de conduta pela qual o indivíduo poderia ser responsabilizado seria aquela que pudesse causar danos aos demais. Sobre si mesmo, seu próprio corpo, suas opiniões etc., deveria haver total autonomia para o indivíduo (MILL,2010).

Nosso objetivo nesse trabalho não é absolutamente a defesa das teorias de Mill, sobre a liberdade individual (o autor pertence a uma corrente teórica denominada utilitarista), mas tão somente constatar a sua preocupação com a proteção da diversidade de cada indivíduo, em face da possibilidade de uma imposição tirânica e castradora por parte da comunidade como um todo. Consoante sua opinião existem nos seres humanos tantas diferenças no que toca às fontes de prazer e mesmo na maneira como se ressentem à dor, etc., que não poderia o Estado, nem a própria comunidade efetuar uma imposição de seus valores sob pena de impedir que seus membros pudessem alcançar qualquer parcela de felicidade ou mesmo desenvolver a sua identidade de forma plena (MILL, 2010) 
Em que pese a importância da construção teórica da Autonomia Privada para a Modernidade, no sentido de oferecer limites à intervenções não desejadas na órbita individual, observamos que a Liberdade, ou o poder de autodeterminação individual aí protegido ficou circunscrito a uma abordagem negativa, ou seja: uma técnica de proteção onde a tutela se restringe a impedir intervenções do Estado ou da sociedade, e o direito de estar só, de ser deixado em paz com a sua diversidade estaria garantido. Essa proteção, ainda nos dias atuais é extremamente importante, sobretudo em face da tecnologia contemporânea bastante desenvolvida, capaz de tornar vulnerável a vida pessoal.

Entretanto estaríamos ainda dentro de uma perspectiva de não intervenção, nos moldes do liberalismo clássico. O que gostaríamos de propor para os dias atuais, como forma de superação dos impasses contemporâneos à emancipação individual, com repercussões para a sociedade como um todo seria a Autonomia Decisória, no que se refere à disponibilidade do próprio corpo (aspecto físico e mental), necessária para a construção da identidade pessoal e proteção da própria dignidade. Nesse sentido, não se estaria pleiteando a tutela de um valor em abstrato, consoante a ótica liberal, atribuído ao indivíduo “natural”, mas uma proteção necessária para um processo de individuação (YOUNG, 1990), com vistas à construção, projeção, e reconhecimento social da personalidade de cada pessoa, na sua diversidade.

Observamos portanto que, o direito de não ser submetido a controle indevido, embora importante para a construção da Autonomia Decisória, não seria suficiente. Deveriam estar presentes outros requisitos, tais como: O Direito ao Corpo (aspecto físico e mental), dentro de uma configuração mais abrangente, o que implicaria no controle efetivo do próprio corpo, essencial para uma percepção íntegra de si mesmo. Consoante Erving Goffman, o sentimento de controle sobre o próprio corpo, para além de ser necessário à própria autoconfiança pessoal é fundamental para a configuração da própria identidade (GOFFMAN, 1971).

A esse respeito, em uma abordagem sobre Autonomia Decisória, mediada pelo corpo Jean Cohen (2012, p. 195) afirma: “nós somos o próprio corpo”, numa tentativa de esclarecer a importância do corpo para a individualidade e identidade pessoal.

A questão da identidade pessoal, ligada ao corpo, como forma de garantia da dignidade pessoal foi utilizada amplamente pelo movimento feminista para defender o direito ao aborto, por exemplo. Nesse sentido afirmam: “nosso corpo, nós mesmas”, pontuando a importância da integridade corporal para efeitos da Autonomia Decisória. O foco central dessa defesa toca a identidade pessoal feminina. Forçar uma mulher a uma gravidez indesejada significaria a imposição de uma identidade não desejada de mulher grávida e de mãe à mulher, promovendo- 


\section{DEBATES CONTEMPORÂNEOS SOBRE AUTONOMIA PRIVADA DECISÓRIA: TRANSGÊNEROS, IDENTIDADE GENÉTICA E EUTANÁSIA}

lhe uma mudança substancial no próprio corpo e em sua identidade pessoal, com reflexos emocionais profundos, para além de alterações significativas de natureza econômica (COHEN, 2012). Daí a importância que adquiriu o termo embodiment, como emblemático da importância da corporificação, nas lutas feministas, que estaria a indicar o próprio corpo como o substrato mais importante da identidade pessoal.

Não temos por objetivo nesse trabalho o tema do aborto, porque então teríamos que esgotá-lo em toda a sua profundidade. Nossa abordagem nesse momento é apenas exemplificativa, buscando esclarecer a relevância da integridade corporal (física e mental) para a integridade da personalidade.

Ainda, no tocante à construção do Direito ao Corpo, como mediador da Autonomia Decisória e da identidade pessoal, nossa preocupação aponta também a necessidade de salvaguardar outro Direito Humano Fundamental, ou seja: O Direito à Informação. Esse apresenta caráter difuso e constitui direito de toda a coletividade à informação. Sem a informação precisa, veiculada de forma clara e sem manipulações não pode haver escolha verdadeira e satisfatória para a construção de uma identidade. O controle sobre o próprio corpo engloba a possibilidade de tomar decisões sobre ele, no que se refere por exemplo: à saúde, questões genéticas, riscos possíveis quanto a ingestão de medicamentos, etc. Assim, informações mais próximas da realidade quanto aos resultados das opções seria fundamental para a construção da identidade pessoal, na medida em que possibilitaria decisões em conformidade com a vontade pessoal.

Nesse sentido também se dá o entendimento de Beauchamp e Childress (2013). Esses autores mencionam a necessidade do respeito ao direito a ter opiniões, apontando que para assegurá-lo, mais do que a não intervenção nas decisões das pessoas deveria haver a informação necessária para que pudessem decidir sem medos, ou outros entraves capazes comprometer o exercício da sua autonomia. Para esses autores, a autonomia estabelece um direito de autoridade para o controle do próprio destino (BEAUCHAMP; CHILDRESS, 2013).

Assim, numa tentativa de redesenhar o conceito e o conteúdo da Autonomia Privada de origem liberal, de modo a melhor adequá-la às necessidades contemporâneas de emancipação social, buscamos redescrevê-la e caracterizá-la de modo a que pudesse se constituir num caminho a ser trilhado para a construção da identidade pessoal. No próximo tópico passaremos então à verificação de suas contribuições para os movimentos sociais nos dias atuais. 


\section{DEBATES COTEMPORÂNEOS SOBRE AUTONOMIA: TRANSGÊNERO, IDENTIDADE GENÉTICA E EUTANÁSIA}

Como já informamos anteriormente, a construção do conceito de Autonomia Decisória foi essencial para a ampliação das lutas feministas levadas a efeito a partir das últimas décadas do século XX. Mais precisamente em 1973, registra-se como marco histórico para elaboração desse conceito uma decisão da Suprema Corte dos Estados Unidos, caso Roe v. Wade. (COHEN, 2012). Essa decisão teve como ponto de partida a discussão sobre o direito da mulher para decidir sobre o aborto, com base no “direito à privacidade”, constitucionalmente protegido.

Naturalmente não estava ainda nesse momento estabelecido o conteúdo da Autonomia Decisória da maneira como o concebemos atualmente, entretanto, discutia-se a privacidade enquanto uma possibilidade para assegurar decisões pessoais, como por exemplo, a liberdade reprodutiva. A partir dessa decisão, passou-se então à interpretação da Autonomia Privada, nos termos de um direito à privacidade pessoal, para garantir que a mulher pudesse efetuar escolhas relacionadas com o seu próprio corpo, tais como: sexualidade, aleitamento, reprodução, etc., redesenhando o seu conteúdo.

Certamente, essa nova interpretação significou um retorno ao privado, o que levou a Autonomia Decisória a ser alvo de muitas desconfianças, inclusive por parte dos movimentos que militavam pela emancipação das mulheres. Foi acusada, num primeiro momento, de reforçar o esteriótipo da dicotomia público / privado, de corte liberal, por (re)colocar as lutas feministas no patamar da privacidade doméstica que tanto havia contribuído para a exclusão das mulheres das decisões políticas, do mercado de trabalho etc., relações precipuamente atribuídas à esfera pública, intensificando as hierarquias sociais entre os sexos. (COHEN, 2012)

De outra parte, também foi objeto de críticas severas por parte dos movimentos sociais, e responsabilizada por reforçar as tendências liberais que buscam promover o apartamento do indivíduo dos valores da sua comunidade . (COHEN, 2010)

Entretanto, não obstante as reações oferecidas à formulação contemporânea da Autonomia Decisória, o que se observa é que sua proposta se distancia substancialmente da perspectiva liberal, no que se refere ao individuo. O que se procura tutelar, por meio da Autonomia Decisória não é absolutamente o indivíduo "natural” considerado em abstrato, para o qual seriam atribuídos valores ideológicos da ética burguesa liberal, como se fossem valores universais da natureza humana. O que se procura garantir por meio da Autonomia Decisória é a construção da identidade pessoal de cada um, a partir da sua diversidade. Trata-se portanto, 


\section{DEBATES CONTEMPORÂNEOS SOBRE AUTONOMIA PRIVADA DECISÓRIA: TRANSGÊNEROS, IDENTIDADE GENÉTICA E EUTANÁSIA}

da proteção indivíduo concreto, considerado na sua singularidade, certamente um processo a ser desenvolvido durante toda a sua vida.

\subsection{TRANSGÊNEROS}

Sem termos como objetivo esgotar, com a profundidade necessária, os aspectos que envolvem o tema da transexualidade nesse momento, esclareço que o nosso intento será apenas o de indicar as possíveis contribuições da Autonomia Decisória para construção e reconhecimento da identidade pessoal do transgênero.

Num primeiro momento, buscaremos a formulação de um conceito operacional para a pessoa transexual, certa de tratar-se de assunto extremamente polêmico.

Dias (2010, p.142) trabalha com a definição de transexualidade como sendo a falta de concordância entre o sexo biológico e o sexo psicológico. Já Vieira (200,p.64), complementando essa definição informa que o transexual possui a convicção de pertencer ao sexo oposto àquele que aparece no seu Registro de Nascimento, e se sente profundamente desconfortável em relação aos seus órgãos sexuais externos, procurando muitas vezes uma cirurgia para adequá-los, ou um tratamento hormonal capaz de levá-lo à aparência externa do sexo oposto, ou ainda poderá optar por ambas alternativas. Teríamos então, como fruto dessa adequação a possibilidade de um transexual masculino ou feminino.

De outra parte, autores como Pinto e Bruns (2009, p.73) afirmam que a transexualidade tem natureza distinta da orientação sexual, e dessa forma haveria a possibilidade para o transgênero de ter orientação afetivo-sexual de natureza heterossexual, homossexual, ou bissexual. Esclarecem ainda que a identidade de gênero do transexual refere-se unicamente ao gênero com o qual ele se identifica e quer ser reconhecido, diferindo da orientação sexual que indicaria o gênero pelo qual se sente atraído sexualmente.

Há que se fazer ainda outra importante distinção em relação à intersexualidade. O intersexual, também conhecido como hermafrodita, apresenta características sexuais de ambos os sexos. Trata-se de uma indeterminação anatômica quanto ao sexo e não uma questão de natureza psicológica, como a intersexualidade.

Para o momento, trataremos unicamente da transexualidade, especialmente no que toca suas principais reivindicações expressas pelos movimentos sociais LGBT, que protagonizam essa luta.

Consoante também ao que é referido pelos movimentos LGBT, não trataremos a transexualidade pelo sufixo “ismo"(transexualismo) porque esse sufixo promoveria uma 
abordagem preconceituosa, caracterizando o transexual como portador de doença. O sufixo “dade”, por outro lado, estaria a indicar o modo de ser da pessoa transexual, terminologia que nos parece mais adequada.

Partindo então das necessidades expressas nas reivindicações dos movimentos LGBT, observamos que, já num primeiro momento, a questão mais emergente apontaria para a necessidade de um processo transexualizador quer através de tratamento hormonal, procurando uma de adequação de sua aparência ao sexo com o qual ele se identifica, e/ ou por meio de uma cirurgia de designação de gênero.

É importante salientar que, a natureza da escolha, a respeito dessas transformações, é absolutamente pessoal, variando de indivíduo para indivíduo. Para alguns transexuais, bastará o tratamento hormonal, para uma transformação externa de sua aparência. Entretanto para outros será realmente necessária, além da ingestão de hormônios, a cirurgia de reconstrução genital. Essa decisão será sempre personalíssima, e deve estar fundamentada na Autonomia Decisória, que seria adequada para tutelar decisões pessoais tomados sobre o próprio corpo, como também embasaria a construção efetiva e necessária da identidade para esses casos.

Entretanto, ocorre que essas demandas estariam no campo da tecnologia médica, e teriam caráter oneroso. Dessa forma a transexualidade foi transformada em uma patologia médica, para que a transformação desejada pudesse ser mais acessível aos transexuais, nos sistemas de saúde. De outra, parte como durante muito tempo a cirurgia de "mudança de sexo" foi considerada uma mutilação, responsabilizando criminalmente o médico que pudesse realizála, considerá-la uma patologia contribuiu para a legalização dessa intervenção médica.

Por outro lado temos que reconhecer que esses "caminhos" construídos pela área médica, ainda que com a anuência dos transexuais, reduziram ou mesmo retiraram da órbita do transexual qualquer possibilidade de decisão sobre as transformações em seu próprio corpo, comprometendo a sua Autonomia Decisória. Decisões de cunho personalíssimo acerca do próprio corpo passaram para a área médica, e ficaram a depender de diagnósticos médicos, avaliação de psicólogos, etc. A medicina, cujo conhecimento técnico e todo o seu aparato tecnológico deveria servir unicamente para informar as pessoas sobre as consequências das intervenções (hormonais e cirúrgicas), invadiu a esfera de decisão pessoal do transexual, e acabou por efetuar escolhas em seu lugar. Não devemos nos esquecer ainda que patologizar a transexualidade sempre reforça o preconceito social e contribui para promover o retrocesso nos valores de toda a sociedade. 


\section{DEBATES CONTEMPORÂNEOS SOBRE AUTONOMIA PRIVADA DECISÓRIA: TRANSGÊNEROS, IDENTIDADE GENÉTICA E EUTANÁSIA}

De outra parte, é preciso que coloquemos em dúvida o próprio binarismo de gênero (masculino e feminino), como um fator de ordem "natural”, como majoritariamente se convencionou (BENTO, 2006). Autores como; Berenice Bento (2006); Judith Butler (2002); Nancy Fraser (2010), entre outros, questionam a sua veracidade e defendem o entendimento de que a orientação sexual e a identidade de gênero são construções sociais. Assim, não existem papéis sexuais essenciais ou biologicamente atribuídos à natureza humana. Consequentemente, seria bastante pertinente indagarmos sobre a validade do próprio processo transexualizador, como forma de alcançar a suposta "normalidade”, e buscar uma relação de pertencimento ao binarismo de gênero.

Nesse sentido, entendemos que a própria patologização da transexualidade levou ao reforço desse binarismo de gênero: ou se é masculino, ou feminino. Qualquer diversidade para além dessas possibilidades é caracterizado como doença. O respeito à Autonomia Decisória poderia contribuir para que a pessoa pudesse se identificar consoante suas características pessoais, sem que se sentisse estigmatizado como um portador de uma doença.

Essas questões referidas acima sobre a transexualidade foram meramente exemplifi cativas, com o escopo de servir à reflexão sobre a aplicabilidade da Autonomia Decisória em questões de identidade.

\subsection{IDENTIDADE GENÉTICA}

Abordaremos, nesse tópico alguns aspectos polêmicos sobre o tema : "reprodução humana assistida heteróloga”, que apresenta regulamentação ainda bastante escassa no ordenamento jurídico brasileiro, com implicações diretas para o Direito Civil, no que toca à filiação, mas que sobretudo promove repercussões profundas e irreversíveis na construção da identidade da pessoa, originada dessa reprodução.

A reprodução humana assistida heteróloga consiste numa técnica de inseminação onde uma terceira pessoa doará seu sêmen para que a mulher venha a ser fecundada. Naturalmente o material biológico não será do pai “presumido”, esposo ou companheiro da mulher. Será de um doador externo e desconhecido para o casal que deseja conceber. Também poderá ocorrer a doação de um óvulo, que uma vez fecundado, seja introduzido no útero da mulher "receptora”. O filho nascido dela, nesse caso, só se ligará biologicamente ao marido ou companheiro, que forneceu o espermatozoide. A mulher, nessa situação, será apenas a “receptora” do óvulo da doadora, fecundado pelo marido. 
Podemos observar então que, em termos exclusivamente biológicos, o pai que forneceu o espermatozoide ou a mãe "receptora" é que seriam verdadeiramente os pais biológicos dessa criança. A questão, objeto da nossa reflexão, seria sobre a possibilidade da pessoa concebida nessas circunstâncias poder conhecer seus pais biológicos.

É importante frisar que a legislação brasileira é bastante exígua a esse respeito. No Brasil, algumas resoluções do Conselho Federal de Medicina, tentaram solucionar a polêmica estabelecendo que o entendimento prevalente é o de garantir o sigilo do doador. Também no direito comparado, o anonimato do doador é regra em todos os países, com exceção da lei sueca, motivada pela necessidade de prevenir doenças e por entender que a pessoa possa, com a maioridade, conhecer o pai biológico.(MACHADO, 2005).

Certamente, a grande motivação que tem norteado esse entendimento procura evitar que o pai, ou a criança, busquem estabelecer relações interpessoais com o objetivo de obter vantagens pecuniárias. (MACHADO, 2005) Nesses casos, especialmente o doador se sentiria desconfortável e desmotivado à doação, com a possibilidade de uma ação na área cível . Para a medicina, naturalmente interessa, é mesmo fundamental que haja doadores. A reprodução humana assistida utiliza-se de uma tecnologia extremante sofisticada e dispendiosa, havendo portanto interesse na sua continuidade, não apenas pelo desenvolvimento tecnológico que ela pode promover, mas também pelo lucro que ela pode gerar. Sem a disponibilidade do doador ou doadora não haveria reprodução humana assistida heteróloga.

Entretanto, em que pese os interesses de ordem econômica capazes de levar à proteção do anonimato, para garantir a presença do doador, a pessoa, produto dessa reprodução parece ter sido colocada em segundo plano. Sua identidade, que certamente estaria na dependência de informações dessa natureza não foi cogitada, na maioria dos países.

Na maior parte dos casos, o filho, produto dessa reprodução heteróloga busca, o conhecimento da sua origem genética por motivos íntimos, psicológicos, que passam a atormentar suas vidas. Certamente isso não ocorrerá com todas pessoas. Entretanto, em muitas situações, a possibilidade de desvendar a sua origem, para conhecer sua estória e construir a sua identidade pode ser extremamente importante.

Consoante a Autonomia Decisória, preceito que entendemos estar plenamente defeso no princípio da Liberdade e no poder de autodeterminação como um direito fundamental na quase totalidade dos países ocidentais, essa necessidade deveria ser sempre tutelada, sob pena do comprometimento da identidade de cada pessoa interessada. 


\section{DEBATES CONTEMPORÂNEOS SOBRE AUTONOMIA PRIVADA DECISÓRIA: TRANSGÊNEROS, IDENTIDADE GENÉTICA E EUTANÁSIA}

Poderia haver um questionamento em relação à vontade do doador de permanecer em sigilo. Naturalmente, essa expectativa é plenamente legítima e pode ser inclusive objeto de contrato para efeitos de doação. Entretanto, deveria ser contemplada também a possibilidade de quebra desse sigilo, para os casos em que tal informação fosse determinante para o filho dessa reprodução. Certamente vantagens pecuniárias, na órbita cível, tais como pensões alimentícias, ou outras situações que pudessem repercutir em ônus para o doador, teriam que ser afastadas através de regulação, entretanto o anonimato não deveria ser imposto pela legislação, nem interpretado de forma absoluta, sob pela de inviabilizar a construção da identidade do interessado.

Ainda em defesa da flexibilização do sigilo contribuiria outro argumento: a própria manutenção da saúde e a prevenção de doenças genéticas para a pessoa originada de reprodução humana assistida. Certamente o direito de saber sobre a sua ascendência biológica para prevenir, ou mesmo curar doença é direito inalienável, contra o qual nenhum ordenamento jurídico pode criar obstáculos.

Pesa ainda, em favor da quebra do sigilo do doador, a flagrante desigualdade de tratamentos promovida em situações de equivalência na regulação brasileira . Estamos nos referindo à discrepância entre a posição assumida pelo Conselho Federal de Medicina e o artigo 27 do Estatuto da Criança e do Adolescente . O artigo 27 estabelece de maneira inequívoca que” o reconhecimento do estado de filiação é direito personalíssimo, indisponível e imprescritível”. Dessa forma, ferindo a própria aplicação do princípio da igualdade, teríamos uma situação de tratamento diferenciado à situações equivalentes, depreciando a condição da criança originada de reprodução assistida heteróloga.

Pelos argumentos apontados constatamos a importância fundamental do respeito à Autonomia Decisória para os filhos de reprodução assistida heteróloga. Sem a sua tutela teríamos o amesquinhamento da sua dignidade pessoal.

\subsection{EUTANÁSIA}

O recorte de abordagem, nessa parte do trabalho será exclusivamente, sobre alguns aspectos polêmicos que permeiam o tema da eutanásia, e do suicídio assistido e as possíveis contribuições que a Autonomia Decisória poderia promover para a elucidação dessas questões.

Antes porém, de tocarmos diretamente quer no tema da eutanásia ou do suicídio assistido, é importante salientarmos que ambos são concebidos como possibilidades para se colocar um fim a uma situação de extremo sofrimento para o paciente em fase terminal. Dessa 
maneira, a antecipação da morte, como forma de se extinguir a dor extrema, que amesquinha a dignidade pessoal do doente é vislumbrada como um caminho para a promoção da sua "morte com dignidade”.

Quando nos referimos ao paciente em estágio terminal por sua vez, estamos indicando uma situação tal de enfermidade, em que já se pode perceber que as condições de saúde do doente não mais serão recuperadas, que a morte virá em curto lapso de tempo, com intenso sofrimento. Assim, a antecipação da morte, seria forma de culminar um processo inexorável de dor, degradação física e psíquica que precisaria chegar ao fim. Em casos dessa natureza teríamos como possibilidade, a tutela do direito à incolumidade física e psíquica. Entendemos que a antecipação da morte por escolha do paciente, seria defensável nessas situações, e estaria fundamentado inclusive, no direito à incolumidade física da pessoa.

Entretanto, no que se refere ao tema antecipação da morte, para os casos de eutanásia e suicídio assistido a fundamentação, objeto do nosso trabalho, é a Autonomia Decisória. Poderíamos perguntar então, se a Autonomia Decisória poderia autorizar, ou justificar o direito de morrer de forma digna, pela eutanásia ou pelo suicídio assistido?

De maneira concisa, apenas para que se estabeleça um conceito operacional para ambas categorias de morte antecipada, objetivando um melhor entendimento das mesmas, passaremos então à verificação de algumas características necessárias ao desenvolvimento do nosso trabalho.

A eutanásia, também conhecida como a "boa morte” é expressão utilizada para indicar uma ação médica que tem por finalidade a abreviação da vida de doentes incuráveis em processo de sofrimento extremo. Parte de uma conduta comissiva do médico, a pedido do paciente (Kovács,2003) que, no exercício de seu poder de autodeterminação busca da antecipação do óbito e tem como objetivo uma morte sem sofrimentos extremos, consoante a seus valores e sua dignidade pessoal.

No suicídio assistido entretanto, o paciente é apenas assistido para a morte. Os atos são praticados pela própria pessoa, no sentido de antecipar a sua morte. A participação de terceiros será indireta, sempre com o consentimento prévio do paciente terminal e por motivos misericordiosos, (SANTORO,2010)

Sabemos entretanto que o ordenamento jurídico brasileiro criminaliza ambas as condutas e dessa forma, seriam à primeira vista condutas inadmissíveis. Entretanto, é necessário que nos lembremos dos ensinamentos de Roberto Lyra Filho, para quem o direito positivo, embora relevante, não possui “todas as cotas de legitimidade da justiça” (LYRA 


\section{DEBATES CONTEMPORÂNEOS SOBRE AUTONOMIA PRIVADA DECISÓRIA: TRANSGÊNEROS, IDENTIDADE GENÉTICA E EUTANÁSIA}

FILHO, 1986). Assim a ordem posta é sempre provisória e passível de alterações. Por outro lado, a própria interpretação dos valores constitucionais, bem como a sua irradiação ao ordenamento jurídico poderiam propor uma interpretação mais consentânea com a autodeterminação e a dignidade pessoal.

Consequentemente, a Autonomia Decisória poderia propor caminhos no sentido de garantir as decisões do paciente no que se refere ao último ato da sua vida, ou seja: escolher morrer com dignidade, para além de determinar o melhor momento e a melhor forma de morrer, consoante os valores por ele assumidos ao longo de sua vida (coerentes com a sua identidade). Decisões dessa natureza, são de cunho íntimo, personalíssimo e implicam certamente no exercício do direito ao próprio corpo. No controle e no empoderamento que o indivíduo deve ter sobre seu corpo físico e mental.

Para tanto, outro direito é fundamental: O direito à informação, que deve ser prestada pelo médico, em relação ao quadro clínico do paciente, bem como sobre as consequências que poderiam advir das suas decisões pessoais, trazendo os dados necessários para que a morte, ocorrida no momento escolhido e consoante os seus próprios valores pudesse representar o fim do seu sofrimento, mas sobretudo uma opção pela dignidade.

È importante também que se observe que, não apenas a morte antecipada (eutanásia e suicídio assistido) fazem parte das possibilidades de escolha do paciente, no exercício da sua Autonomia Decisória. Poderia optar também pela distanásia e pela ortotanásia.

Sem ter também a pretensão de esgotar a temática acerca das possibilidades elencadas, no que toca à morte digna, (não é o objetivo do nosso trabalho) passaremos a expor algumas características das categorias mencionadas, de modo a promover melhor compreensão.

Compreende-se distanásia, a partir das considerações a respeito da atuação do médico, ou da equipe médica responsável. É identificada quando se constata a opção pela conservação da vida do paciente em estágio terminal a qualquer custo. Também é conhecida como “obstinação terapêutica”, onde se observa tentativa de prolongar a vida do paciente de forma injustificada, para os casos de morte irreversível. Naturalmente, alongar a própria vida, ainda que através de procedimentos dolorosos, pode ser opção legítima do paciente, no exercício da sua Autonomia Decisória. Entretanto, quando a conduta adotada pela área médica impõe ao paciente medidas extremas sem o seu consentimento e com o desrespeito inclusive da sua autodeterminação, passa não ser conduta razoável e, de forma nenhuma deve ser aceita (BEAUCHAMP; CHILDRESS, 2013) 
Temos também a possibilidade da ortotanásia como opção para o paciente terminal. Esta seria uma morte ocorrida naturalmente, sem prolongamentos desnecessários e dolorosos, não se tratando portanto de morte antecipada . Pressupõe entretanto procedimentos médicos paliativos, administrados para o doente, capazes de diminuir a sua dor e trazer-lhe conforto.

Em que pese ser defensável para o paciente a sua opção pelo suicídio assistido ou pela eutanásia, inclusive como forma de garantia da sua dignidade pessoal, é preciso que consideremos a posição do médico, no que toca o exercício também da sua Autonomia Decisória. Não se pode esquecer que o profissional médico pode opor objeção, à realização da eutanásia e/ou suicídio assistido, (Vieira, 2009). Para esses casos, ainda que não houvesse proibição legal, e repúdio expresso em Código de Ética Médica, como ocorre no Brasil, mesmo assim o médico poderia arguir escusa de consciência, para não executá-las e nessas situações , não estaria obrigado. Passaria a conduta a outro médico que com ela estivesse de acordo.

Poderíamos concluir, a respeito da morte antecipada, com fundamento no princípio constitucional da Autonomia Decisória, pela necessidade de uma mudança de paradigmas na legislação pátria, bem como na hermenêutica constitucional e irradiação de seus princípios para o ordenamento jurídico. Só assim, poderíamos garantir sua efetivação, especialmente para os casos de sofrimento extremo do paciente terminal. De outra parte é preciso que se entenda a morte como o último ato a ser tomado em vida, e assim, deve ser necessariamente uma manifestação da Autonomia Decisória da pessoa, para que ela possa vivê-lo consoante os princípios e valores que sempre nortearam a sua vida e constituem a sua identidade.

\section{A CONSTRUÇÃo DE UM MODELO DE PROTEÇÃO DA AUTONOMIA PRIVADA DECISÓRIA COMO MECANISMO DE INFLUÊNCIA REGIONAL DO BRASIL}

Como foi possível ver acima, a reconfiguração do Direito ao próprio corpo com ênfase na ótica da Autonomia Privada Decisória é essencial para um empoderamento do individuo, e por consequência, da construção de uma sociedade mais consciente e efetivamente igualitária. Essas características, todavia, são úteis não só para a superação de impasses sociais, mas, sobretudo, para dar ao Estado e sua sociedade ferramentas de sociabilidade que respeitadas e aplicadas de forma contínua passam a ser consideradas valores nacionais.

Diante desse cenário e do crescente interesse do Estado brasileiro em aumentar sua influência internacional, entendemos que mais eficaz do que ferramentas de poder tradicionais 


\section{DEBATES CONTEMPORÂNEOS SOBRE AUTONOMIA PRIVADA DECISÓRIA: TRANSGÊNEROS, IDENTIDADE GENÉTICA E EUTANÁSIA}

- como armas e exército - se faz necessário entender como elementos institucionais (oficiais e oficiosos) podem ser mais efetivos na construção de identidades e, consequentemente, de poder e influência no sistema internacional (WENDT, 2014).

Como afirma Joseph Nye (2004) o chamado soft power ${ }^{3}$, vai agrupar elementos que dentro da interação entre os atores no sistema internacional, podem criar influência e aproximar parceiros, de modo que o poder exercido por um determinado Estado não necessariamente reflita em submissão e perda para outro. Para isso, Nye afirma que o soft power possui três elementos de poder que o formam: cultura, valores políticos e política externa.

Assim, frente às aspirações do Brasil, de construir para si próprio mais influência e poder no sistema internacional, promover a reconfiguração de direitos que corroborem com um arcabouço de empoderamento do individuo e de sua liberdade, e ao mesmo tempo, conseguir efetivar tais modificações como parte dos valores políticos e da cultura nacional, segundo Nye (2004) pode ter um efeito de disseminador de valores e, consequentemente, de aumento de influência e poder do Brasil no sistema.

Todavia, é fato que o Brasil é um país com sérias debilidades - econômicas, políticas e sociais - para inserir-se internacionalmente de forma autônoma, assim, o cenário ideal para o exercício dessa influência seria seu entorno estratégico, ou seja, a América do Sul. Porém, essa influência para ter efeito de aproximação e criação de identidade tem que trabalhar numa lógica de ganhos absolutos (WENDT, 2014), fazendo com que tais parceiros regionais vejam no Brasil, e nas suas políticas, uma possibilidade de emancipação e efetivação dos seus próprios interesses.

\section{CONSIDERAÇÕES FINAIS}

Numa perspectiva de identificar alguns impasses importantes colocados frente às lutas por emancipação social, do final do século XX, o presente artigo buscou resgatá-las na sua origem, com o objetivo de construir possíveis caminhos para a superação de seus entraves na atualidade.

Nesse sentido, observamos que para esses movimentos sociais, da era considerada póssocialista (década de noventa do século passado), estava claro que a luta por redistribuição de riquezas travada até então pelos movimentos operários tradicionais, não seria suficiente para garantir respectivamente o reconhecimento das suas diversidades enquanto grupo social. Dessa

\footnotetext{
${ }^{3}$ O termo é utilizado no português como “poder brando”.
} 
forma, emergiram com reivindicações distintas e forte poder de conflito, pleiteando o reconhecimento de suas diferenças quanto à etnia, orientação sexual, questões de gênero, o direito de dispor sobre o seu próprio corpo, etc.

Contudo, pudemos observar que apesar das postulações serem distintas das tradicionais demandas dos trabalhadores nos conflitos capital/trabalho, as expectativas para a satisfação de suas necessidades ainda estavam voltadas para os mecanismos de intervenção e regulação do Estado Social de Bem Estar , e nisso havia plena identidade com os movimentos sindicalistas operários do século XX.

Ocorre, entretanto que a essa época o Estado Social de Bem Estar, motivado pelo fenômeno da globalização na economia e pela internacionalização do capital já havia promovido erosão significativa na sua estrutura, promovendo a retração nos seus mecanismos de intervenção e pacificação social, consoante a proposta neoliberal, inclusive flexibilizando e desregulando direitos sociais. Dessa forma, pleitear a emancipação social através da regulação, tornou-se, cada vez mais inviável, tanto para os movimentos operários tradicionais quanto para os movimentos que pleiteavam o reconhecimento da sua diversidade.

A partir de então, algumas tendências foram observadas nas lutas sociais desses novos movimentos: o aprofundamento das reivindicações em prol do reconhecimento; o abandono progressivo das lutas pela redistribuição de riquezas e o desinteresse na construção de um projeto comum emancipatório. Essas opções contribuíram, de outra parte para a segregação e o separatismo entre os movimentos sociais, repercutindo decisivamente para o esvaziamento de seu poder conflitual, com prejuízo para as lutas emancipatórias e para a sociedade de maneira geral.

Uma vez identificados os desafios enfrentados pelas lutas travadas em prol da inclusão social, nosso trabalho centrou-se no desenvolvimento das bases teóricas relativas à Autonomia Privada Decisória, com base na privacidade decisória, procurando verificar a sua contribuição teórica para os movimentos sociais que postulam o Direito ao próprio corpo. Dessa forma, buscamos caso a caso, uma reflexão sobre os possíveis avanços que a construção da identidade pessoal, com base na Autonomia Privada Decisória, poderia trazer para as lutas em prol da libertação.

Assim, numa tentativa de redesenhar o conceito e o conteúdo da Autonomia Privada de origem liberal, de modo a melhor adequá-la às necessidades contemporâneas de emancipação social, buscamos (re)descrevê-la e caracterizá-la de modo a que pudesse se constituir num caminho a ser trilhado para a construção da identidade pessoal e não apenas, como havia sido 


\section{DEBATES CONTEMPORÂNEOS SOBRE AUTONOMIA PRIVADA DECISÓRIA: TRANSGÊNEROS, IDENTIDADE GENÉTICA E EUTANÁSIA}

até então no ideário liberal, somente uma esfera de não intervenção, para a proteção de identidades frágeis. Nesse sentido concluímos ainda que de fato, para a construção da identidade pessoal deveria ser tutelada a possibilidade de empoderamento do próprio corpo (direito ao corpo no aspecto físico e mental) considerando a sua singularidade, e o direito à informação, para que se pudesse fazer escolhas que atendessem as suas necessidades na construção da sua identidade pessoal, com autodeterminação plena e sem intervenções, nem do Estado, nem da própria sociedade.

A partir daí, procuramos verificar de que maneira poderia contribuir a Autonomia Privada Decisória para a construção da identidade de grupos sociais que pleiteiam o reconhecimento das suas diferenças, tais como os transgêneros. Para esse grupo social, que apresenta, entre outras, a característica fundamental de incompatibilidade de gênero em relação ao seu sexo biológico, observamos que a construção da identidade, com base na Autonomia Privada Decisória poderia fundamentar o direito à realização de um tratamento hormonal, pura e simplesmente, à depender das necessidades de cada pessoa transgênera, e em muitos casos, o direito a uma cirurgia de adequação sexual. Constatamos também, a importância da alteração do nome, no Registro Civil, para a grande maioria de pessoas desse segmento. Todas as possibilidades acima descritas, a depender das necessidades específicas de cada um. Em todas essas situações, a Autonomia Privada Decisória seria essencial para fundamentar direitos, na construção da identidade pessoal.

Posteriormente, verificamos a aplicação da Autonomia Privada Decisória para pacientes terminais, em situações específicas descritas em nosso trabalho, e observamos que poderia justificar inclusive a realização da eutanásia, enquanto última decisão a ser tomada sobre própria vida e sobre o próprio corpo, de modo a que o paciente em sofrimento e sem possibilidade de recuperar a sua saúde, pudesse viver os últimos momentos da sua vida consoante os princípios e valores que sempre nortearam a sua vida e constituíram a sua identidade.

Nesse sentido, também pudemos constatar a contribuição fundamental da Autonomia Privada Decisória para aquelas pessoas, advindas de reprodução humana assistida, que postulam o conhecimento da sua identidade genética, essencial para solucionar problemas genéticos de saúde, ou mesmo procuram ter acesso à informações relativas a sua filiação biológica, para os casos em que o desconhecimento quanto à própria origem , poderá significar sofrimento e transtorno para a sua saúde mental, inviabilizando a construção de sua identidade de forma saudável. 
Por fim, argumentamos que esse processo de construção emancipatória ao tornar-se parte da cultura e dos valores políticos nacionais pode servir de ferramenta para promover uma inclusão cada vez mais decisória nas esferas internacionais, e que o melhor espaço para que tal premissa se concretize seria o entorno estratégico brasileiro, ou seja, a América do Sul, lugar onde as identidades são transversais e podem trabalhar em prol de um benefício coletivo entre as partes.

\section{REFERÊNCIAS BIBLIOGRAFIA}

ARENDT, Hannah. A Origem do Totalitarismo. São Paulo: Companhia das Letras, 1998.

BARROSO, Luís Roberto. Prefácio. In: SARMENTO, Daniel (org). Interesses públicos versus interesses privados: desconstruindo o princípio da supremacia do interesse público. Rio de Janeiro: Lumen Juris, 2005.

BEAUCHAMP, Tom L.; CHILDRESS, James F .Princípios de Etica Biomédica. Tradução de Luciana Pudenzi.3.ed. São Paulo: Loyola ,2013.574p. Tradução de Principles of Biomedical Ethics.

BEAUVOIR, Simone de. O segundo sexo: a experiência vivida. 7. ed. Rio de Janeiro: Nova Fronteira, 1949, v.2.

BENTO, Berenice. A reinvenção do corpo: sexualidade e gênero na experiência transexual. Rio de Janeiro: Garamond, 2006.

. Na escola se aprende que a diferença faz a diferença. In: Estudos Feministas. Florianópolis, 19(2): 336, mai-ago/2011. Disponível em: http://www.scielo.br. Acesso em 20/01/2016.

BERKMAN, Ricardo Rabinovich. Sobre o direito relacionado à Identidade sexual e aspectos relacionados. In: JUBILUT, Liliana Lyra; BAHIA, Alexandre Gustavo Melo Franco; MAGALHÃES, José Luiz Quadros de (coord). Direito à diferença: aspectos de proteção específica às minorias e aos grupos vulneráveis. Vol 2. São Paulo: Saraiva, 2013.

BERLIN, I. Quatro ensaios sobre a liberdade. Tradução Wumberto Hudson Ferreira. Brasília, DF: Ed. da UNB, 1981.

BUTLER, Judith. Bodies that Matter - On the discursive limits of "sex". New York: Routledge, 1993.

Críticamente subversiva. In: JIMÉNEZ, Rafael M. Mérida. Sexualidades transgresoras: Una antología de estudios queer. Barcelona: Icária editorial, 2002, p. 55 a 81.

Problemas de gênero. Feminismo e subversão da identidade. Rio de Janeiro: Civilização Brasileira, 2003. 


\section{DEBATES CONTEMPORÂNEOS SOBRE AUTONOMIA PRIVADA DECISÓRIA: TRANSGÊNEROS, IDENTIDADE GENÉTICA E EUTANÁSIA}

COHEN, Jean L. Repensando a privacidade: autonomia, identidade e a controvérsia sobre 0 aborto.In: Revista Brasileira de Ciência Política, nº7, Brasília, jan-abr de 2012. p 165.

CONSTANT, Benjamin. Da Liberdade dos Antigos Comparada a dos Modernos. Disponível em: < http:www.fafich.ufmg.br' luarnaut Constant-liberdade. Pdf > Acesso em 25 de outubro 2016.

COULANGES, F. A cidade antiga. Lisboa: Clássica, 1971.

DIAS, M.B. União Homoafetiva: o preconceito e a justiça. São Paulo: Revista dos Tribunais, 2009.

FRASER, N. Redistribuição, reconhecimento e participação: por uma concepção integrada da justiça. In: SARMENTO, D.; IKAWA, D.; PIOVESAN, F. (orgs.). Igualdade, diferença e direitos humanos. Rio de Janeiro: Lúmen Júris, 2008, p. 167-190.

GOFFMAN, Erving. “The nature of deference and demeanor” Interaction ritual: essays on face-to-face behavior. Nova Iroque: Pantheon, 1967.

HABERMAS, Jurgen. O Discurso filosófico da Modernidade: doze lições. Tradução Luiz Sérgio Repa, Ronei Nascimento. São Paulo: Martins Fontes, 2002.

HAUSMAN, B. Changing Sex: Transsexualism, thechnology and the Idea of Gender. Durham: Duke University Press, 1995.

HONNETH, Axel. Integridade e desrespeito: princípios para uma concepção de moralidade baseada na teoria do reconhecimento. In: TEIXEIRA, Anderson Vichinkeski; OLIVEIRA, Elton Somensi de (Org.). Correntes Contemporâneas do Pensamento Jurídico. Barueri: Manole, 2010. Cap. 6. p. 115-132.

LOURO, Guacira Lopes. O corpo estranho: Ensaios sobre sexualidade e teoria queer. Belo Horizonte: Autêntica, 2004.

LYRA FILHO, Roberto. O Que é Direito. São Paulo. Brasiliense: 1985.

MACHADO, Maria Helena. Reprodução Humana Assistida: aspectos éticos e jurídicos. Curitiba: Juruá, 2005.

MEIRELES, Rose Melo Venceslau. Autonomia privada e dignidade humana. Rio de Janeiro: Renovar, 2009.

MILL, John Stuart. Sobre a Liberdade. São Paulo: Hedra, 2010.

NYE, J. Soft Power - The means to success in word politics. New York: PublicAffairs, 2004.

PINTO, Maria Jaqueline Coelho; BURNS, Maria Alves de Toledo. Trans Géneros: uma abordagem sociológica da diversidade. Lisboa, 2009

PRATA, Ana. A Tutela Constitucional da Autonomia Privada. Coimbra: Almedina, 1982. 
SANTORO, L.de F. Morte Digna: o direito do paciente terminal. Curitiba: Juruá, 2010, p.118.

SANTOS, Boaventura de Sousa. A Difícil Democracia: Reinventar as Esquerdas. São Paulo: Boitempo, 2016.

VIEIRA, Tereza Rodrigues. Nome e Sexo. Mudança no Registro Civil. São Paulo: Revista dos Tribunais, 2008,

YOUNG, Iris. Justice and the politics of difference. Princeton: Princeton University Press, 1990.

WENDT, A. Teoria Social da Política Internacional. Rio de Janeiro: Editora PUCRio, 2014. 